\title{
Gamified Text Messaging Contingent on Device-Measured Steps: Randomized Feasibility Study of a Physical Activity Intervention for Cancer Survivors
}

Michael C Robertson ${ }^{1,2}$, MPH; Elizabeth J Lyons ${ }^{3}, \mathrm{PhD}, \mathrm{MPH}$; Yue Liao ${ }^{1,4}$, PhD, MPH; Miranda L Baum ${ }^{1}$, MA; Karen M Basen-Engquist ${ }^{1}$, PhD, MPH

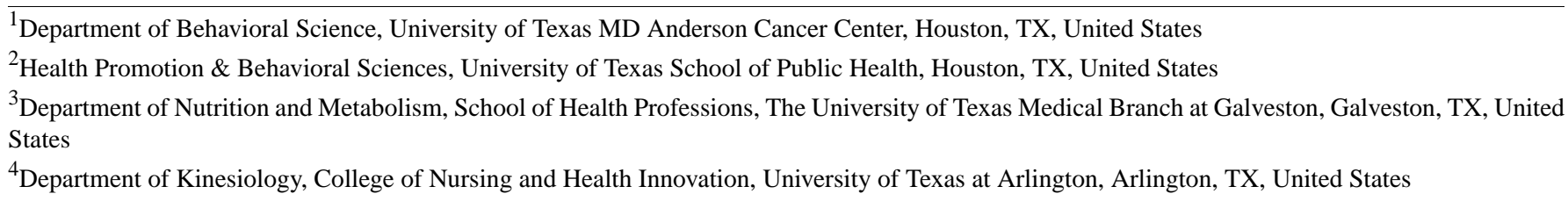

Corresponding Author:

Karen M Basen-Engquist, PhD, MPH

Department of Behavioral Science

University of Texas MD Anderson Cancer Center

1515 Holcombe Blvd

Houston, TX, 77030

United States

Phone: 17137453123

Email: kbasenen@mdanderson.org

\section{Abstract}

Background: Physical activity can confer diverse benefits on cancer survivors. Unfortunately, many cancer survivors are not sufficiently active. The efficacy of physical activity interventions for this population may be increased by grounding them in Self-Determination Theory (SDT). Combining game design elements with wearable technologies may be a useful and scalable approach to targeting SDT constructs to promote cancer survivors' physical activity.

Objective: The primary aim of this study is to evaluate the feasibility and acceptability of Steps2Health, a physical activity intervention for cancer survivors. It also aims to investigate the effects of the intervention on motivation, physical activity, and step count.

Methods: We randomized 78 insufficiently active cancer survivors to an experimental or comparison group. All participants received a physical activity tracker. The experimental group participants also received a set sequence of multimedia messaging service messages that were triggered in real time by meeting predetermined cumulative step count totals. Messages presented information about a virtual journey and included photographs and vivid descriptions of locations to increase autonomous motivation. Additional messages targeted perceptions of relatedness (eg, role modeling) and competence (eg, facilitating mastery experiences). We administered pre- and postintervention surveys and conducted 15 individual interviews to evaluate the intervention. We performed directed content analysis of qualitative data and conducted mixed effects linear modeling to investigate participants' changes in motivation, self-reported physical activity, and device-measured step counts.

Results: There was minimal loss to follow-up (3/78, 4\%), the device wear rate was high $(2548 / 3044,83.71 \%$ of days), and technical problems with messaging based on real-time step counts were limited. Our qualitative data analysis revealed 3 overarching themes: accessibility, autonomous motivation, and relatedness. Participants successfully navigated the technological aspects and game design elements of the intervention. Participants found messages targeting autonomous motivation and competence or self-efficacy to be enjoyable and compelling, but one feasibility criterion for participant engagement (response rate to text messages) was not met. Messages targeting relatedness were less highly rated than the messages targeting autonomous motivation and competence or self-efficacy. During the intervention, both groups increased their motivation for physical activity $(B=0.16 ; 95 \%$ CI 0.01 to $0.30 ; P=.04 ; d=0.49)$, and assignment to the experimental group was associated with increased self-reported leisure activity score $(B=10.78 ; 95 \%$ CI 3.54 to $18.02 ; P=.005 ; d=0.64)$. The experimental group had greater increases in daily step counts over time $(B=322.08 ; 95 \%$ CI 54.01 to $590.15 ; P=.02 ; d=0.28)$. 
Conclusions: This study supports the feasibility of using real-time game design elements to target SDT constructs and increase cancer survivors' physical activity. Overall, our findings support the acceptability of the Steps2Health intervention, but fostering active participant engagement and targeting relatedness may present additional challenges. Steps 2 Health may help cancer survivors increase their physical activity levels.

(JMIR Mhealth Uhealth 2020;8(11):e18364) doi: $10.2196 / 18364$

\section{KEYWORDS}

cancer survivors; physical activity; motivation; self-control; mobile health; mobile phone; technology

\section{Introduction}

\section{Background}

Physical activity is generally safe and a health protective factor for cancer survivors. It is associated with a lower risk of all-cause mortality in this population, and for survivors of some types of cancer, it is associated with lower risks of recurrence and cancer-related mortality [1]. Increasing moderate-to-vigorous physical activity may ameliorate symptoms that cancer survivors commonly report, including fatigue, pain, anxiety, decreased physical functioning, and cancer-related cognitive impairment [2]. Unfortunately, the majority of cancer survivors do not meet the nationally recommended aerobic physical activity guidelines for adults [3], which call for engaging in 150 min of moderate-intensity aerobic physical activity or $75 \mathrm{~min}$ of vigorous-intensity aerobic physical activity (or some equivalent combination of both) per week. An analysis of data from adult cancer survivors responding to the 2014 National Health Interview Survey indicated that under $45 \%$ of adult survivors aged $45-64$ years met the guidelines for aerobic physical activity, and this percentage was approximately $35 \%$ in survivors 65 years and older [4]. Studies using accelerometers to objectively measure physical activity guideline adherence indicate that this percentage may be between $4 \%$ and $13 \%$ [5,6]. Cancer survivors may encounter barriers that impede physical activity guideline adherence faced by the general population (eg, competing demands for time) and additional barriers attributable to cancer and its treatment. These can include decreased physical functioning, fatigue, and pain [7,8].

Electronically delivered behavioral interventions have been shown to be effective in promoting physical activity in cancer survivors [9]. Such interventions readily lend themselves to widespread dissemination and increasingly feature mobile and wearable computing technologies (mobile health [mHealth]) that can provide timely feedback on behavior. Although behavioral interventions incorporating wearable consumer technologies have been used to initiate physical activity among cancer survivors [10], evidence of the long-term effectiveness of these interventions is lacking. Furthermore, most mHealth programs have high discontinuation rates (eg, 25\% of users abandon mobile apps after just a single use) [11]. Many mHealth programs are centered on facilitating self-regulatory processes (eg, goal setting, self-monitoring) but are not necessarily designed to affect participants' motivation for physical activity. This is an important distinction, particularly because cancer survivors may face barriers that can diminish their motivation to engage in physical activity (eg, decreased physical functioning, fatigue, pain) [7,8]. Increasing cancer survivors' motivation for physical activity may facilitate sustained engagement with mHealth programs and improve long-term behavioral adherence to recommended guidelines [12].

Self-Determination Theory (SDT) provides a framework for understanding the role of quality of one's motivation in long-term adherence to health-related lifestyle behaviors [13]. It posits that motivation can be conceptualized as existing on a continuum that ranges from fully external or controlled motivation to fully internal or autonomous motivation and that increasing the latter tends to yield longer lasting behavioral change than the former [13]. SDT also holds that autonomous regulation is determined in large part by the satisfaction of an individual's core psychological needs (autonomy, relatedness, and competence) [13]. This theoretical approach can be useful in predicting and influencing physical activity in the general population [14], and targeting SDT constructs may be similarly beneficial for promoting physical activity in cancer survivors [15]. Indeed, SDT is increasingly being used to inform interventions in this population $[16,17]$.

One approach that has been used to effectively target SDT constructs in the general population is gamification, the application of game design elements to nongame contexts [18-20]. Thus, we drew from the games-for-health literature to develop Steps 2 Health, an mHealth intervention that targets SDT constructs to promote cancer survivors' physical activity. As only few models for systematic planning of gamification interventions exist [21], we adapted the Behaviour Change Wheel model for this purpose [22]. This model typically asks planners to match intervention functions (eg, persuasion) to theoretical constructs (eg, reflective motivation). Our adaptation included playful experiences taken from the Playful Experiences Framework [23] as potential intervention functions. We chose to focus on playful experiences as broad methods of intervention (rather than game mechanics as specific behavior change techniques) to emphasize the autonomy-supportive, playful aspects of games, as has been recommended [21,24]. Specifically, we focused on the playful experiences of discovery, exploration, and humor to target intrinsic regulation. In addition, we included techniques from Motivational Interviewing and Acceptance and Commitment Therapy to complement the game messages and target integrated regulation [25,26].

\section{Objectives}

The main purpose of this study is to assess the feasibility of Steps 2 Health and the participating cancer survivors' satisfaction with it. Its secondary objective is to assess the effects of Steps2Health on participants' autonomous regulation, 
self-reported physical activity, and device-measured physical activity (ie, step counts).

\section{Methods}

\section{Recruitment}

We identified potential participants through various means, including health fairs, conferences, and other local events in South Texas; social media (eg, Facebook, Twitter); and our institutional website and publications. We contacted interested individuals via email and telephone and conducted a formal screening process via telephone. We engaged in a verbal informed consent process with all eligible individuals between September 2018 and February 2019. All research protocols were approved by the University of Texas MD Anderson Cancer Center's Institutional Review Board (protocol 2018-0239). Participants were adult cancer survivors who had completed primary cancer treatment for at least three months previously, owned a smartphone, and were willing to receive text messages and complete web-based surveys. Eligible participants did not meet the recommended physical activity levels [27] at screening as determined by verbal administration of the modified Godin Leisure-Time Exercise Questionnaire [28].

\section{Study Design}

We conducted a randomized controlled pilot trial. As the intervention duration was contingent on participants' cumulative step count (ie, participants who registered more daily steps progressed though the intervention more quickly), we assigned participants to the experimental and comparison groups in pairs. We recruited cohorts of 6 participants (to facilitate the logistics of study operations) and randomly assigned pairs within each cohort and group assignment within each pair (ie, for each group of 6 participants, we randomly assigned each participant to 1 of 3 pairs, and for each pair, we randomly assigned one participant to the experimental group and the other to the comparison group). The study staff conducted this restricted randomization procedure using Research Electronic Data Capture (Vanderbilt University). The intervention duration for both participants in each pair was determined by the experimental group participant's time to reach a predetermined cumulative step count (see the Intervention section). We administered surveys before and after the intervention. For each pair, we continued to record participants' step counts for 4 weeks after the experimental group participant had completed the intervention. The participants assigned to the control arm completed baseline and follow-up assessments in the same timeframe as their paired counterpart (ie, the Intervention section details the study duration for each pair determined by the activity level of the experimental group participant).

We conducted individual, semistructured interviews with 15 experimental group participants at the end of their study participation. Questions were centered on obtaining feedback on the feasibility and acceptability of the intervention and insights into how it may be improved (Multimedia Appendix 1). We interviewed some participants who completed the intervention most quickly and some who completed it least quickly. We interviewed additional participants at the discretion of the principal investigator (eg, to ensure that we interviewed some men). Each interview lasted for 30 to $60 \mathrm{~min}$, and all interviews were conducted by the first author (MR). The study staff (MB) took detailed notes in all interviews. Immediately after the interview, the first author reviewed and contributed to these notes. We performed qualitative data collection until there was consensus among the research team that the point of data saturation had been reached and the individual interviews were not producing novel content any longer.

\section{Intervention}

All participants engaged in this study remotely. We synchronized wrist-worn Fitbit Alta devices to Fitabase (Small Steps Laps), a web-based data management platform for wearable devices, and then mailed each participant a device. We instructed participants to wear the device during waking hours. We included instructions and links to the Fitbit content detailing how to set up the Fitbit device to synchronize automatically. All participants had access to the Fitbit website and app. In addition, the participants in the experimental group received Steps 2 Health multimedia messaging service (MMS) messages that were designed to target SDT constructs. These messages, which were developed by the research team, presented information about a virtual journey through Japan's Inland Sea region and were triggered by step counts in real time. Participants' progress on the 166,000-step (approximately 83 miles) virtual journey was determined by cumulative step counts measured by the Fitbit devices. All experimental group participants received the same series of text messages. The duration of the Steps 2 Health intervention was determined by how long it took participants to register 166,000 steps on their device (ie, if participants were more active, they received the messages more frequently). We chose this distance because we anticipated that it would take most participants about 1 month to complete the journey. We designed the Steps2Health intervention to have a variable duration contingent on participant step count to facilitate a sense of autonomy for the user and verisimilitude for the gamified intervention's premise of undertaking an actual journey in real time. There is only one journey featured in this pilot study, but ultimately, Steps 2 Health may feature a variety of journey options that users can engage in sequentially for a more continuous experience.

The Steps2Health intervention included 54 total messaging blocks designed to target autonomous regulation, autonomy, relatedness, and competence (Multimedia Appendix 2). Messages were informed by insight from previous qualitative research in cancer survivors and developed in a consensus-building process among the research team, which has expertise in health behavior change theory and physical activity promotion for cancer survivors [29]. All messaging blocks contained text, and some additionally contained images or hyperlinks (Table 1). Each block included 1 to 3 messages. Messages targeting autonomous regulation presented photographs and vivid descriptions of destinations along a geographically accurate virtual tour of the region. These messages presented playful experiences of exploration, discovery, and humor and encouraged participants to identify value-based life goals linked to physical activity (Table 1). Some messages contained hyperlinks to various resources for healthy living (eg, videos demonstrating muscle strengthening 
exercises, healthy recipes local to the current virtual location, stress-reduction techniques, etc). We designed the Steps 2 Health intervention to most heavily target this construct (devoting 21 of 54 messaging blocks to it), given its emphasis on SDT and its central role in the gamification elements of the intervention. Participants were also given the choice to participate in additional mini journeys (13 messaging blocks). These optional messages were similar to those targeting autonomous regulation. To target the SDT construct of relatedness, we included messages in 10 messaging blocks from Ruby, an ovarian cancer survivor (this was a fictitious character, and participants were made aware of this). This character was written to be a positive role model. Her messages provided encouragement and prompted participants to reflect on questions that were derived from motivational interviewing principles to elicit positive change talk [26]. Finally, 10 messaging blocks included messages adapted from previous studies to increase participants' competence or self-efficacy for increasing physical activity.

Table 1. Example messages targeting Self-Determination Theory constructs.

\begin{tabular}{ll}
\hline Step count & Example messages \\
\hline 1 & - $\quad$ Welcome to Steps 2 Health! \\
- & $\begin{array}{l}\text { Please save this number in your phone as Steps } 2 \text { Health, and be sure } \\
\text { that your Fitbit is up set to sync automatically. }\end{array}$ \\
- $\quad \begin{array}{l}\text { Bridges serve as major checkpoints for this } 83 \text { mile island-hopping } \\
\text { trek through beautiful Japanese islands. Keep your step count high } \\
\text { to maximize your progress! }\end{array}$
\end{tabular}

8000

- RUBY: Hello! My name is Ruby. I am an ovarian cancer survivor and have already completed this journey.

- I wanted to get strong to keep up with my grandson.

- Is there a goal you'd like to work toward?

- Would you share it with me in a text? If not, just text 0 .

- Would you like to take a quick trip to Onomichi, the "Town of Hills and Cats" today? You'll get some extra photos of high points of Onomichi.

- $\quad$ Reply YES or NO

- You have made it to the beautiful Kosanji temple. It was built in 1936 by a wealthy industrialist in honor of his mother!

- It is written in a famous haiku:

- The mothers of the world are as the Goddess of Mercy. manage the stress. Even a 10-minute time-out can help by taking time to move and breathe.

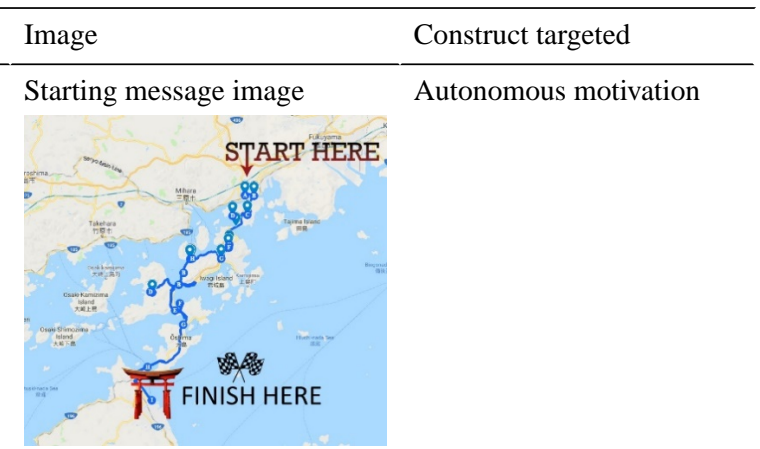

Relatedness example message Relatedness image

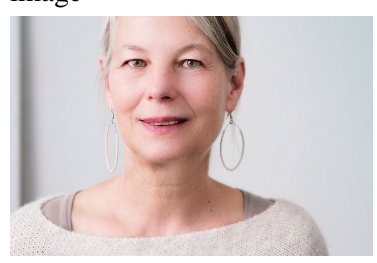

N/A ${ }^{a}$

Autonomy or autonomous motivation

Autonomous motivation exam- Autonomous motivation ple message image

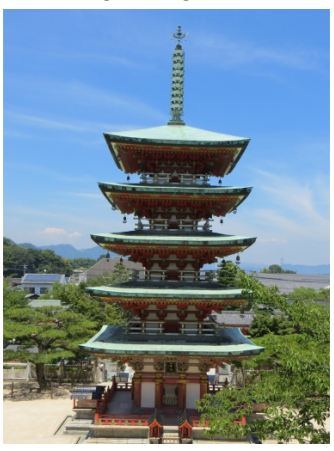

N/A

Competence or self-efficacy

\section{${ }^{\mathrm{a}}$ N/A: not applicable.}

We used Fitabase to gather participants' data in real time from the Fitbit server. We worked with Mosio to build a platform to send intervention text messages on the basis of participants' real-time step counts. This platform queried Fitabase twice an hour to determine participants' cumulative step counts. We ensured that participants enabled their devices to frequently and automatically upload current data to the Fitbit server (ie, synchronize with the server). The text messaging platform sent automatic text message reminders for participants to synchronize 
their devices if they had not done so in 2 days or more, and study staff sent email reminders after 5 days.

\section{Outcomes}

\section{Overview}

For the primary aim of this study, we evaluated intervention feasibility and acceptability via quantitative and qualitative methods. For the secondary aim, we evaluated changes in autonomous regulation, self-reported moderate-to-vigorous physical activity, and device-measured step count over the course of the intervention period. We administered web-based surveys to each participant at baseline and after the experimental group participants completed the Steps2Health intervention. The surveys contained items pertaining to participants' characteristics, the feasibility of the intervention, and participants' autonomous motivation and physical activity.

\section{Intervention Feasibility}

We evaluated feasibility by assessing whether (1) more than $75 \%$ (59/78) of all participants wore their Fitbit at least 5 days a week for at least $75 \%$ of the study period (valid wear); (2) less than $30 \%(23 / 78)$ of all participants reported technical difficulties with the Fitbit or receipt of the text messages (technical difficulties); (3) the experimental group participants responded to at least $80.1 \%$ (157/196) of the messages requiring a response (participant engagement); and (4) at least $75 \%$ (30/39) of the experimental group participants reported that they would recommend the program to friends or family (participant satisfaction). These criteria were derived from metrics for assessing the feasibility of consumer-based wearable physical activity trackers used in other digital behavior change studies [30] and our intervention's theoretical orientation.

\section{Autonomous Regulation}

We administered the Behavioral Regulation for Exercise Questionnaire-3 (BREQ-3) to all participants before and after the intervention. BREQ-3 has acceptable internal consistency [31]. As SDT posits that autonomous regulation is composed of identified regulation, integrated regulation, and intrinsic regulation, we averaged these subscale scores to represent this construct [13].

\section{Physical Activity}

We administered the Godin Leisure-Time Exercise Questionnaire and calculated the Leisure Score Index to measure participants' moderate-to-vigorous-intensity physical activity [28]. This survey has minimal participant burden, good test-retest reliability (reliability coefficient $=0.81$ ), and convergent validity with $\mathrm{VO}_{2} \max$ (maximum rate of oxygen consumption during intense exercise) $[28,32]$. In addition, we evaluated participants' daily Fitbit step count trends. In consideration of the insufficiently active sample recruited in this study and to maximize the use of available data, we used 2 variables to define nonvalid wear days. We defined a nonvalid wear day as a day during which participants (1) did not wear the device for at least 10 hours (out of the full 24-hour day) according to minute-level device data and (2) registered fewer than 1500 steps according to day-level data [33-35]. Minute-level nonwear was defined as periods of 90 consecutive minutes of 0 steps with a 2-min nonzero tolerance, consistent with commonly used accelerometer protocols [36]. We used a combination of day- and minute-level data because some research indicates that the use of accelerometer protocols for minute-level data may tend to overestimate nonwear in Fitbit data [37], and Fitbit devices are programmed to automatically delete minute-level data when their batteries run low or if the devices are not regularly synchronized. Thus, we supplemented this decision rule with the 1500 steps day-level threshold used in other studies [34,35].

\section{Data Analysis}

Two analysts (MR and MB) conducted directed content analysis [38] of the field notes from the individual interviews. We created and assigned inductive and deductive codes to discrete points made by each participant. We organized these codes in an iterative process to gain insight into the perceived feasibility and acceptability of the intervention and means by which the intervention might be improved.

We calculated descriptive statistics for participant characteristics and feasibility items and performed Pearson chi-square tests to evaluate differences in descriptive characteristics between groups. We used linear mixed models to assess between-group differences in pre- to postintervention changes in autonomous regulation (as assessed using the BREQ-3) and physical activity (as assessed using the Godin Leisure-Time Exercise Questionnaire Leisure Score Index). These models included terms for group-by-time interactions with random coefficients for participants nested within pairs. We used a linear growth model with random intercepts and slopes to assess between-group differences in changes in Fitbit-measured step counts during the intervention [39]. As the intervention duration varied among pairs, we modeled each participant's average daily step count as a function of quartiles of the intervention period. We specified an autoregressive covariance structure because of the time series nature of the data and adjusted for the number of days of valid Fitbit wear. We used the maximum likelihood estimation for all linear mixed models. We performed a likelihood ratio test to determine if it was necessary to specify the third level in the linear growth model (pairs subsuming individuals). The results of this test did not show a statistically significant difference in model fit between the 3-level model and a 2-level model $(P=.90)$; furthermore, the conclusions to be drawn from the results of the competing models were not substantively different. Accordingly, we present results from the more parsimonious 2-level model with observations nested in individuals. We created plots recommended by Bolger and Laurenceau [40] to analyze and present the linear growth model results. We supplemented the mixed model findings with Cohen $d$ effect size calculations. We set the nominal $\alpha$ value to .05 for all analyses, which we performed in $\mathrm{R}$ version 3.6.1.

\section{Results}

\section{Participants}

We randomized 78 participants to either the experimental group or comparison group. Of these 78 participants, 3 (4\%) were lost to follow-up and 75 (96\%) completed the baseline and follow-up surveys (Figure 1). The study sample was mostly female (71/78, 
91\%) and relatively well educated (Table 2). The participants' mean age was 55.1 (SD 13.5) years. Most participants were breast cancer survivors $(45 / 78,58 \%)$ and overweight $(38 / 75$, $50 \%$ ) or obese $(19 / 75,25 \%)$. The overall mean time since cancer diagnosis was 9.4 (SD 7.3) years. All participants in the experimental group who completed the preintervention survey also completed the 166,000-step journey.

Figure 1. The CONSORT (Consolidated Standards of Reporting Trials) diagram for Steps2Health recruitment, retention, and analysis.

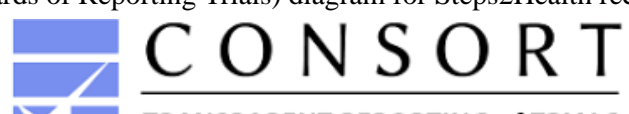

TRANSPARENT REPORTING of TRIALS

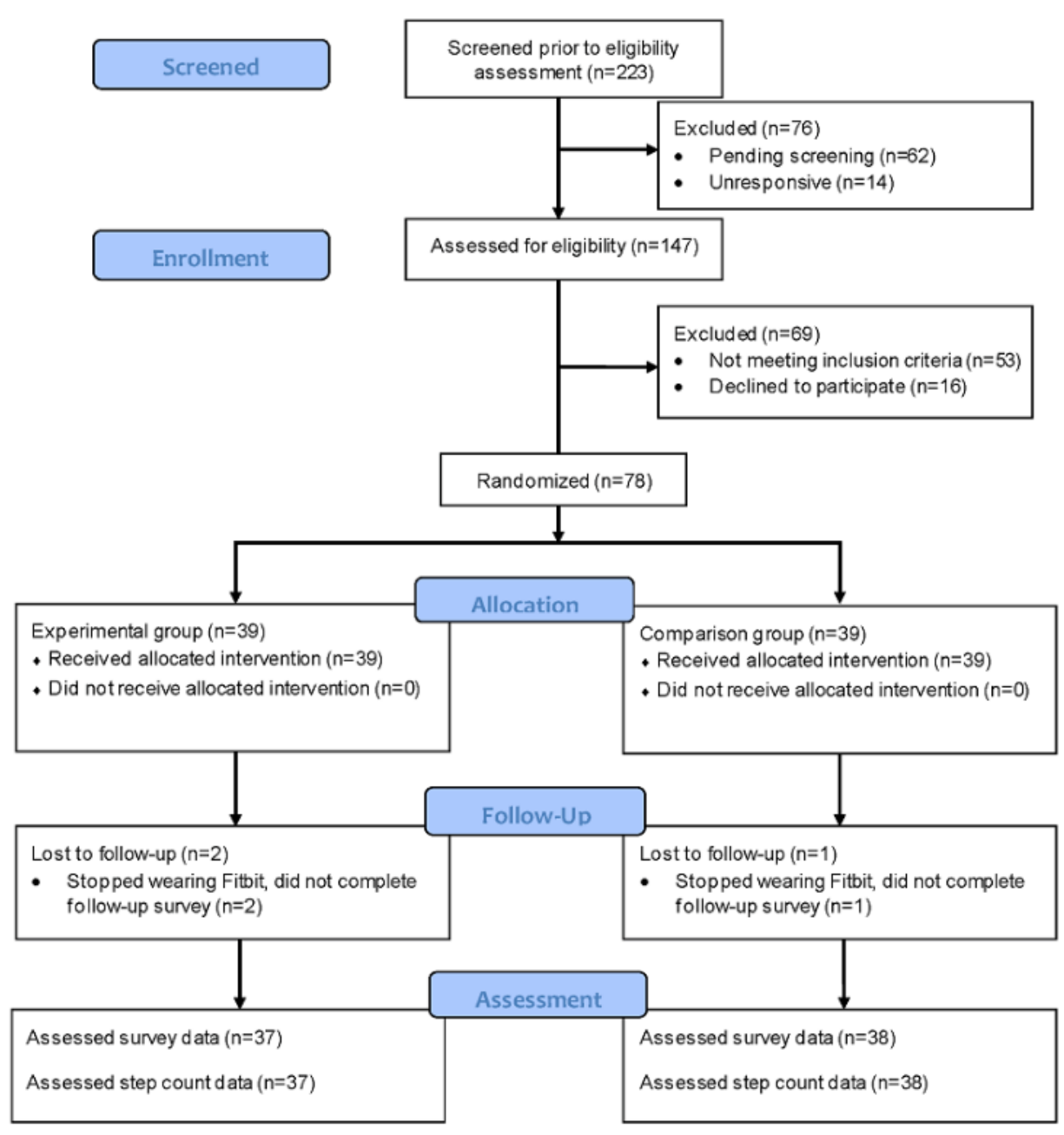


Table 2. Participant characteristics $(\mathrm{N}=78)$.

\begin{tabular}{|c|c|c|c|}
\hline Characteristics & Experimental group, n (\%) & Comparison group, $\mathrm{n}(\%)$ & $P$ value $^{\mathrm{a}}$ \\
\hline Age (years) & & & .89 \\
\hline $18-34$ & $2(5)$ & $2(5)$ & \\
\hline $35-49$ & $10(26)$ & $14(36)$ & \\
\hline $50-64$ & $13(33)$ & $12(31)$ & \\
\hline $65-74$ & $13(33)$ & $10(26)$ & \\
\hline$\geq 75$ & $1(3)$ & $1(3)$ & \\
\hline Education level & & & .16 \\
\hline$<$ High school & $0(0)$ & $1(3)$ & \\
\hline High school diploma or general educational development & $5(13)$ & $2(5)$ & \\
\hline Some college & $11(28)$ & $12(31)$ & \\
\hline Bachelor's degree & $14(36)$ & $10(26)$ & \\
\hline Graduate school degree & $9(23)$ & $14(36)$ & \\
\hline Employment status & & & .98 \\
\hline Employed full time & $15(34)$ & $18(42)$ & \\
\hline Employed part time & $8(18)$ & $6(14)$ & \\
\hline Not employed for pay, not seeking paid employment & $2(5)$ & $1(2)$ & \\
\hline Not employed for pay, but seeking paid employment & $2(5)$ & $1(2)$ & \\
\hline Retired & $8(18)$ & $7(16)$ & \\
\hline Homemaker & $6(14)$ & $7(16)$ & \\
\hline Student & $1(2)$ & $1(2)$ & \\
\hline Volunteer & $2(5)$ & $2(5)$ & \\
\hline Gender & & & .99 \\
\hline Female & $36(92)$ & $35(90)$ & \\
\hline Male & $3(8)$ & $4(10)$ & \\
\hline Marital status & & & .62 \\
\hline Single & $9(23)$ & $5(13)$ & \\
\hline Married & $23(59)$ & $24(62)$ & \\
\hline Divorced & $6(15)$ & $9(23)$ & \\
\hline Widowed & $1(3)$ & $1(3)$ & \\
\hline Race & & & .50 \\
\hline American Indian or Alaska native & $1(3)$ & $0(0)$ & \\
\hline Asian & $0(0)$ & $0(0)$ & \\
\hline Black or African American & $8(21)$ & $6(15)$ & \\
\hline White & $30(77)$ & $32(82)$ & \\
\hline Other & $0(0)$ & $1(3)$ & \\
\hline Ethnicity $^{\text {b }}$ & & & .57 \\
\hline Hispanic & $8(21)$ & $7(18)$ & \\
\hline Non-Hispanic & $30(79)$ & $32(82)$ & \\
\hline Cancer diagnosis & & & .46 \\
\hline Breast & $20(51)$ & $25(64)$ & \\
\hline Ovarian & $4(10)$ & $3(7)$ & \\
\hline
\end{tabular}




\begin{tabular}{llll}
\hline Characteristics & Experimental group, $\mathrm{n}(\%)$ & Comparison group, $\mathrm{n}(\%)$ & $P$ value $^{\mathrm{a}}$ \\
\hline Colorectal & $1(3)$ & $3(7)$ & \\
Endometrial & $6(15)$ & $2(5)$ & \\
Prostate & $2(5)$ & $2(5)$ \\
Urinary tract & $0(0)$ & $1(2)$ \\
Renal or pelvic & $1(3)$ & $0(0)$ \\
Brain & $0(0)$ & $1(2)$ & .51 \\
Other & $6(15)$ & $6(15)$ & \\
Body mass index status & $\mathbf{c}$ & & \\
Normal & $11(30)$ & $7(18)$ & \\
Overweight & $17(46)$ & $21(55)$ & $10(26)$ \\
Obese & $9(24)$ & \\
\hline
\end{tabular}

${ }^{\mathrm{a}}$ Pearson chi-square test.

${ }^{\mathrm{b}}$ Over $98 \%$ (77/78) responded to this item.

${ }^{\mathrm{c}}$ Over $96 \%$ (75/78) responded to required items.

\section{Device Wear}

The median number of days to complete the journey for experimental group participants was 30; this ranged from 15 to 128 days (IQR 23-51). The overall day-level percentage of valid Fitbit device wear was $83.71 \%$ (2548/3044). At the week level, $79 \%(59 / 75)$ of participants wore their Fitbit at least 5 days a week for at least $75 \%$ of the overall study period. This exceeded the a priori target of $>75 \%$, supporting the feasibility of intervention. During the intervention period, the average percentage of nonvalid wear days was $13.5 \%$ for the experimental group and $8.8 \%$ for the comparison group. During the follow-up period, these percentages were $27.5 \%$ and $20.1 \%$, respectively.

\section{Intervention Feasibility}

We conducted in-depth interviews with 15 participants in the experimental group (12 females and 3 males). Qualitative data analysis revealed 3 overarching themes: accessibility, autonomous motivation, and relatedness.

\section{Theme 1: Accessibility}

\section{Limited Technical Difficulties}

Findings from qualitative and quantitative data analyses indicated that participating cancer survivors perceived the
Steps 2 Health intervention to be accessible. Regarding the intervention's technological aspects, participants perceived the intervention to be straightforward and practicable. One participant stated:

Not a single issue. Worked straight up no problem...it was remarkable to me that there were no issues at all. [P60]

This sentiment is generally supported by participants' survey data. Quantitative data revealed that only $11 \%$ (8/74) of participants indicated that they had problems with using the Fitbit device, and only 14\% (10/74) indicated that they had problems receiving the text messages (Figure 2). These numbers were below the a priori target of $<30 \%$, supporting intervention feasibility. Technical difficulties included 4 instances of faulty hardware; in each case, the Fitbit customer support team ultimately replaced the device. One early technical issue was that the MMS messages requiring a response were repeated. This was remedied for the third (6 persons) cohort of participants. There was one instance when all intervention messages were sent at once to a participant. With the participant's permission, we were able to get this person resituated on the journey. 
Figure 2. Participant satisfaction with the Steps2Health intervention.

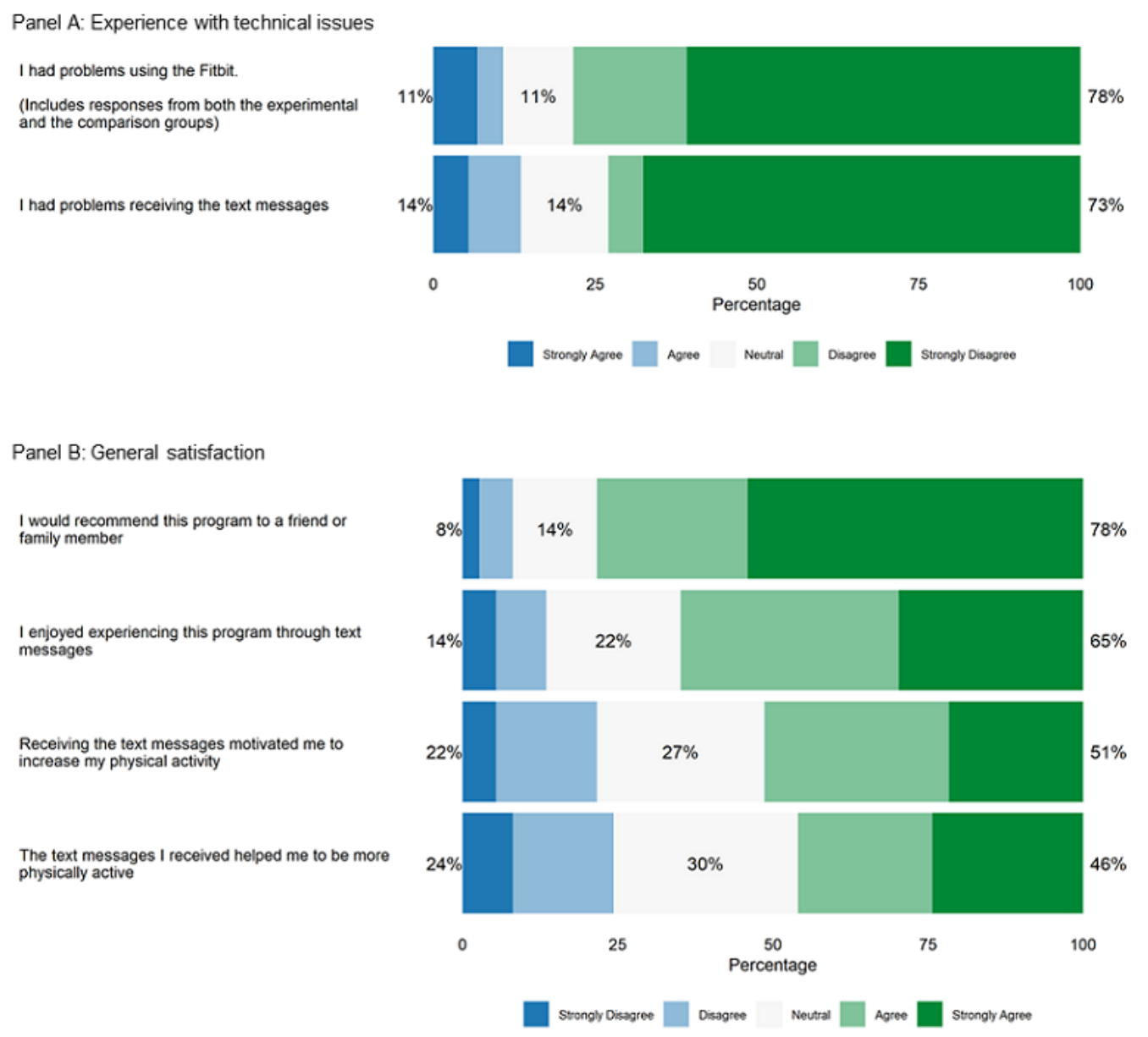

Panel C: Satisfaction with specific types of messages The text messages with practical content for
increasing physical activity or confidence levels were useful to me

The messages about the destinations presented at the journey checkpoints were enjoyable to me

The text messages about the destinations presented at the day trips were enjoyable to me

The text messages from Ruby were enjoyable to me
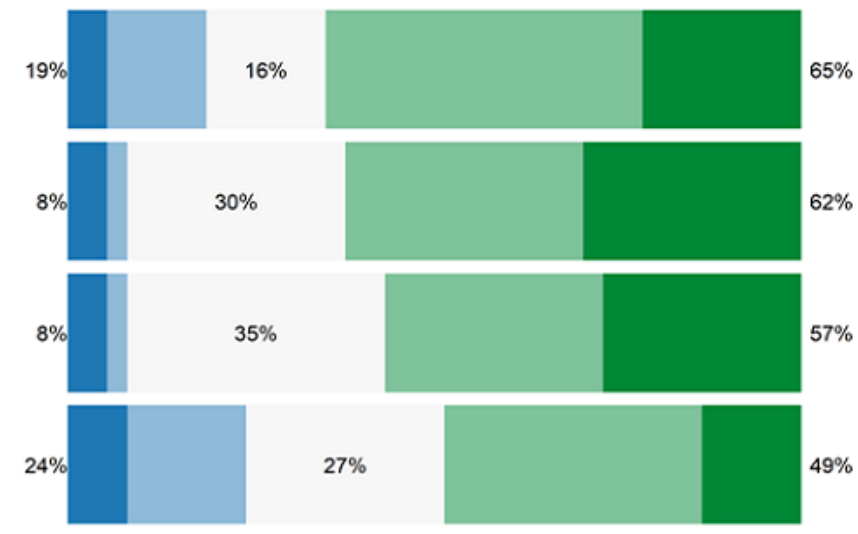

$35 \%$
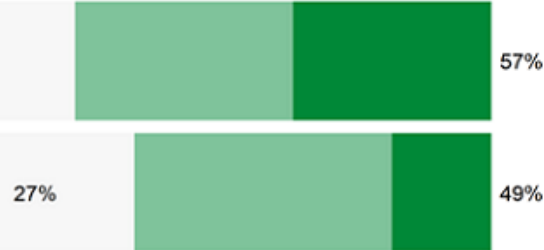

Strongly Disagree
During interviews, several participants suggested providing a more thorough orientation process that would more fully reveal exactly how the text messaging platform worked. In general, participants who offered this suggestion reported that if they did not synchronize their devices frequently, they would receive a burst of several text message blocks in quick succession when they next synchronized their devices. Participants who experienced this said that a more thorough understanding of the intervention messaging mechanism would help them to better navigate these instances and encourage them to synchronize their devices more regularly.

\section{Celebratory Orientation}

Participants appreciated the Steps2Health design that celebrated participants meeting their cumulative physical activity accomplishments and rewarded them with fun and interesting content. This orientation to physical activity promotion made the Steps2Health intervention feel like an accessible program 
that accommodates participants' fitness levels. One participant said:

\section{I'm not real big on exercising and it (Steps2Health) definitely was encouraging. One thing (that was encouraging) was hitting your markers when you've made it there, and there was interesting information... Having that didn't overwhelm me and I could make the markers they were setting up for me. [P22]}

A few participants noted that they appreciated that the Fitbit device gave them credit for steps when they were walking without their smartphones, and some stated that they wished the Steps 2 Health intervention would also be able to celebrate achievements in other forms of exercise that did not necessarily increase step count (eg, swimming).

\section{Theme 2: Autonomous Motivation}

\section{Enjoyment of Journey Messages}

Messages targeting autonomous regulation and competence or self-efficacy received the highest ratings in the follow-up survey (Figure 2). These messages comprised the bulk of the Steps 2 Health intervention. Participants generally found the intervention to be enjoyable and compelling. In total, $78 \%$ (29/37) of participants reported that they would recommend the intervention to a friend or family member (Figure 2). This met the a priori target of $>75 \%$, supporting the feasibility of the intervention.

In individual interviews, 14 of the 15 participants (93\%) said that they would participate in another journey if offered. Some interviewees indicated that they were motivated to be more active to see what was next on the journey. One participant said:

It's very easy in survivorship to have the world be overwhelming, you fall behind. You move slower than before, and it helped keep it a priority. This was very helpful-some of these messages were really pleasant, and I wanted to see what was going to come next. [P60]

Another participant said:

I am coming from a year where fitness wasn't my strong point after treatment but I enjoyed the messages and was sad that it ended...I was excited to read the messages, I talked about them with my kids and it was like a family event. I showed them the milestones about the bridges we crossed. It was really neat. [P29]

However, a few participants said that the text messages were not very enjoyable or motivating to them. One said:

Text messages were annoying — they came at random so I blocked it. [P34]

Despite this, the Fitbit feedback and app functions were almost universally well received.

\section{Linked Media Content}

The use of linked media content in the messages was almost categorically cited as being a good idea, but in individual interviews, many participants said that they did not often access the links. The primary reason given for this was that the participants were too busy to give these messages enough attention when they were received. Participants appreciated that the content would remain in their text message history, but many said that they seldom went back to access them. Recommendations from participants included providing a more readily accessible repository of this content and providing messages that were more individually relevant or personally tailored (eg, messages of prescriptions of physical activity that take into account the user's general fitness level, personal preferences, and/or mobility limitations).

\section{Motivation for Physical Activity}

Although participants in general seem to have enjoyed the intervention content, results concerning whether participants felt the text messages effectively motivated them to engage in more physical activity were mixed. When asked in individual interviews, participants tended to respond that the messages did make them feel more motivated to exercise. However, qualitative data analysis suggested that participants often did not disentangle the effects of the Steps2Health intervention messages from those provided by the Fitbit device or app (eg, messaging from the Fitbit device that is provided if or when the user reaches 10,000 steps in a day). Furthermore, the results of the quantitative data analysis were mixed, with $51 \%$ (19/37) of the sample agreeing or strongly agreeing with the statement "Receiving the text messages motivated me to increase my physical activity," whereas $22 \%$ (8/37) disagreed or strongly disagreed with this statement and $27 \%$ (10/37) indicated they were neutral (Figure 2).

\section{Participant Engagement}

Some intervention messages explicitly requested a response, and in this study, we conceptualized participant engagement as the response patterns to these intervention messages. Messages requesting a response targeted either autonomy or relatedness. The response rate for the former was 73\% (45/62) and that for the latter was $36.7 \%$ (79/215). These results did not meet the a priori target of $>80 \%$ and did not support intervention feasibility. In individual interviews, participants indicated that they were sometimes unaware that they had missed these texts. This may have been partly because of the fact that these text messages could sometimes become buried by subsequent messages if participants were particularly active or if they had not synchronized their devices in a while. Participants indicated that they were often on the move when these messages were received and were unable or unwilling to attend to the messages at that time. The response rate for messages pertaining to relatedness was particularly low, possibly owing to lower participant satisfaction with these messages, detailed below.

\section{Theme 3: Relatedness}

Participants' satisfaction with the intervention messages targeting relatedness was mixed. Quantitative data indicated that these messages were less well received than the other types of messages, with $24 \%$ (9/37) of participants disagreeing or strongly disagreeing with the statement, "The text messages from Ruby were enjoyable to me" (the least well rated of the specific types of messages, as shown in Figure 2). In individual 
interviews, some participants were very positive about this aspect of the program:

I was waiting for those messages every day... I feel like [Ruby] was my coach. [P30]

Some reported that they did not believe that this approach had much utility in fostering feelings of relatedness; one participant said:

Ruby, I just didn't do well on that. I am not one of those people who does a lot of texting. [P68]

Others said that they liked the idea of having a supportive role model but became disillusioned with this aspect of the intervention when they received only brief, automatic replies in response to the thoughtful messages they sent.

As noted earlier, the participant response rate to questions that explicitly requested a response was low $(79 / 215,36.7 \%)$. During interviews, participants offered several suggestions for improving this aspect of the intervention. One suggestion was to avoid using generic replies to participant responses to mimic an actual conversation. Another suggestion was to provide multiple character avatars for users to choose from, which might enhance relatability:

The idea of selecting among two or three (role models) would be awesome, and that may be all you need. At most four. We aren't going to be chatting, so don't try to make it feel like we are chatting. [P60]

This point was emphasized by the male survivors we interviewed, who felt they did not have much in common with the female role model character. To foster feelings of relatedness, some participants suggested making use of text messaging or social media platforms to connect users to one another. One participant said:

If we could do a group text... that way maybe if someone was having a hard day we could encourage each other. [P4]
However, this notion was met with mixed opinions. According to another participant:

My trust level in terms of responding to other people I do not know-I just don't do that. [P68]

\section{Intervention Effects}

\section{Autonomous Regulation}

There was a small, statistically significant effect of time such that participants' autonomous regulation scores tended to increase by $8 \%$ from before to after the intervention $(\mathrm{B}=0.16$; $95 \%$ CI 0.01 to $0.30 ; P=.04 ; d=0.49$ ). The results did not support a group-by-time interaction for autonomous regulation $(P=.59)$.

\section{Godin Leisure-Time Exercise Questionnaire}

Linear mixed model results indicated a statistically significant group-by-time interaction for physical activity as measured by the Godin Leisure-Time Exercise Questionnaire ( $\mathrm{B}=10.78 ; 95 \%$ CI 3.54 to $18.02 ; P=.005)$. Assignment to the experimental group was associated with increased self-reported physical activity behaviors $(d=0.64)$. On average, participants in the experimental group had an increase of $52 \%$ in their Godin Leisure-Time Exercise Questionnaire score, whereas participants in the comparison group tended to have a slight decrease in their score (Multimedia Appendix 3).

\section{Step Count}

The intraclass correlation coefficient for participants' mean daily step count per journey quartile was 0.73 (95\% CI 0.64 to $0.81)$. The linear growth model results indicated a statistically significant group-by-time interaction for step count during the intervention (Table 3; Multimedia Appendices 4-6). The experimental group participants were more likely to increase their step counts during the intervention $(d=0.28)$ than the comparison group participants, and this trend extended into the follow-up period (Figure 3). The linear growth model suggested that the experimental group participants tended to have a lower step count earlier in the intervention than the comparison group participants, but this difference was not statistically significant. 
Table 3. Parameter estimates for the linear growth model of the mean daily step count per intervention quartile as a function of group assignment.

\begin{tabular}{|c|c|c|c|c|}
\hline Effect & Estimate SE & SE & $P$ value & $95 \% \mathrm{CI}$ \\
\hline \multicolumn{5}{|l|}{ Fixed } \\
\hline Intercept & 6473.46 & 324.26 & $<.001$ & 5837.91 to 7109.01 \\
\hline Time & -107.41 & 96.06 & .27 & -295.69 to 80.87 \\
\hline Group & -885.80 & 466.38 & .06 & -1799.90 to 28.30 \\
\hline Days of valid wear & -287.14 & 227.86 & .21 & -733.75 to 159.47 \\
\hline Group by time & 322.08 & 136.77 & .02 & 54.01 to 590.15 \\
\hline \multicolumn{5}{|c|}{ Random at level 2 (between persons) $^{a}$} \\
\hline Intercept & $2,648,712$ & 628,223 & $<.001$ & $1,417,395$ to $3,880,029$ \\
\hline Slope for time & 1284 & 21,090 & .48 & $-40,052$ to 42,620 \\
\hline \multicolumn{5}{|c|}{ Random at level 1 (within person) ${ }^{b}$} \\
\hline Residual & $1,399,430$ & 207,992 & $<.001$ & 991,766 to $1,807,094$ \\
\hline
\end{tabular}

${ }^{\mathrm{a}}$ The correlation between the intercept and slope for time was 0.90 .

${ }^{\mathrm{b}}$ The autocorrelation was 0.21 .

Figure 3. Mean device-measured daily step counts with linear trend lines by group over the study period. Quartiles are presented for the intervention period because the intervention duration differed for each pair. The median intervention period was 30 days (IQR 23-51 days).

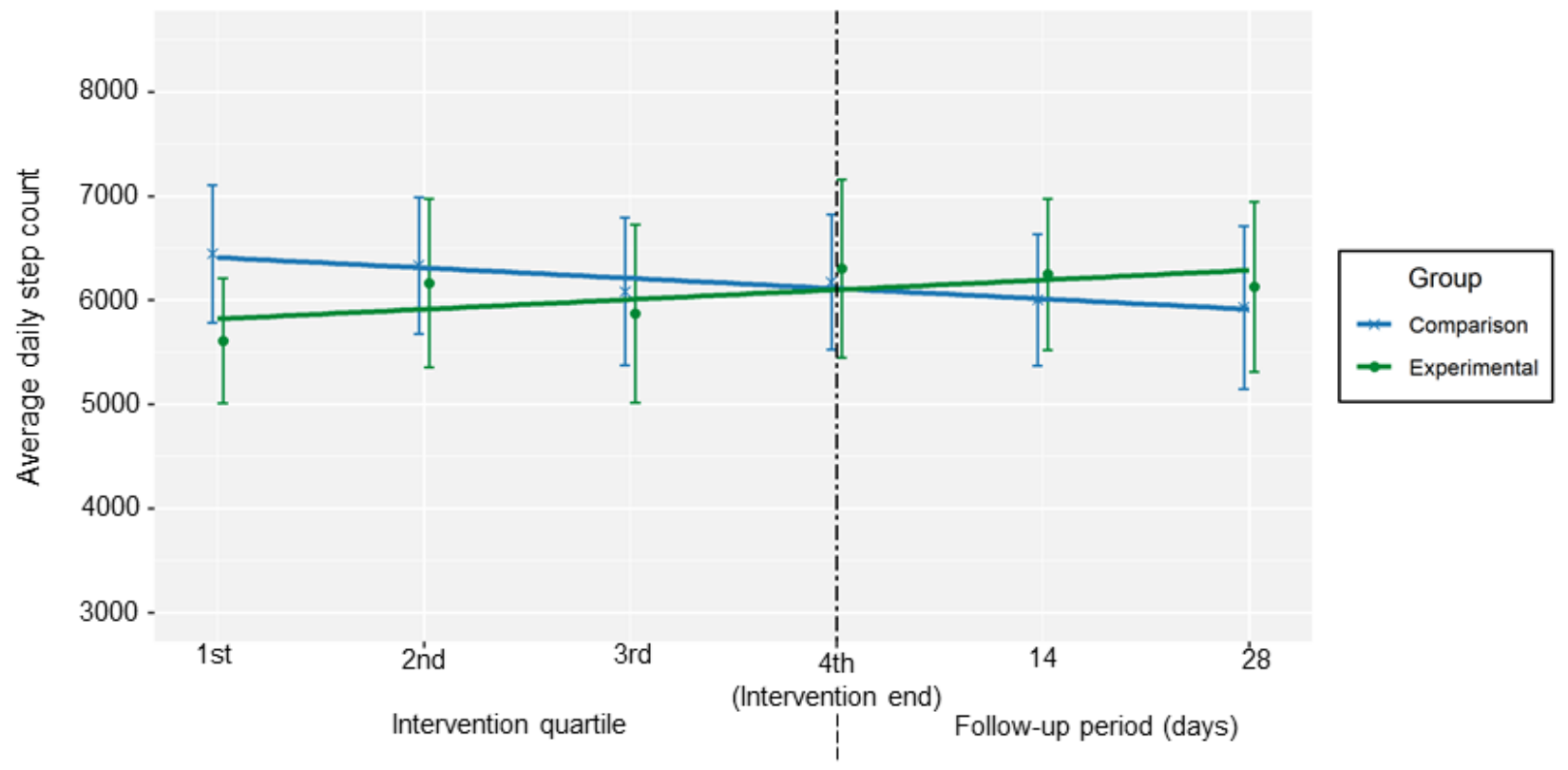

\section{Discussion}

\section{Principal Findings and Comparison With Prior Work}

Steps 2 Health is a physical activity intervention that pairs game design elements with wearable mHealth technologies to target SDT constructs. In general, the results of our study support the feasibility of sending text messages for physical activity promotion contingent on real-time step counts to insufficiently active cancer survivors. One exception is that the participants' response rate to the text messages requesting a response was low; this corroborates previous literature that has identified participant engagement as a challenge to mHealth interventions $[41,42]$. Our results also corroborate previous studies' findings supporting the feasibility and acceptability of behavioral interventions centered on providing wearables to cancer survivors to promote their physical activity [43]. Over $96 \%$ (75/78) of the participants in this study completed the intervention, and similar to other studies, the percentage of valid wear time of the Fitbit device in this study sample was high $[43,44]$. Participants generally rated their satisfaction with the intervention as high but had mixed ratings for aspects of the intervention centered on targeting relatedness. Questionnaire data suggested that the Steps 2 Health intervention increased self-reported moderate-to-vigorous physical activity levels from pre- to postintervention. Device-measured data suggested that the Steps2Health intervention was associated with a greater increase in daily step count over the course of the study period; 
the comparison group appeared to have a higher step count early in the intervention period, which steadily declined, whereas the experimental group had a lower step count early on, which steadily increased.

The game design elements of the Steps 2 Health intervention are in line with the recommendation by Nicholson [45] that, to foster long-term behavior change, gamified intervention approaches should be centered on providing information that engenders meaningful connections. Beyond providing performance feedback, which may not always be relevant to insufficiently active cancer survivors [29], the Steps2Health intervention messages were designed to build autonomous motivation by fostering curiosity, unexpected adventures, and playfulness in the context of cancer survivorship. The results of this study support the general acceptability of this approach and the feasibility of using the approach in real time. Survey and qualitative data from individual interviews indicated that participants found the messages targeting autonomous motivation to be pleasant and compelling and that they would recommend the experience to friends and family. The messages targeting autonomy and competence or self-efficacy were also well rated.

Compared with the messages targeting autonomy and competence or self-efficacy, the messages targeting relatedness were not as well received, and the feasibility criterion associated with the response rate to these messages was not met. Enhancing relatedness has the potential to promote physical activity in cancer survivors; however, the marked heterogeneity of this population introduces challenges $[29,46]$. Some individuals may be more receptive to having this need fulfilled by constructive social support, whereas others may benefit more from healthy competition [47]. The incorporation of more granular, individualized tailoring may enable future mHealth interventions to meet this need for a greater diversity of individuals. In this study, participants recommended providing multiple role model characters to choose from, which they felt would help to enhance relatability. Anticipating our study sample, we created a female role model, but our findings support the notion emphasized in previous literature that participant self-tailoring may foster individual autonomy and connection to digital interventions (eg, allowing users to choose role models whose background and story most resonate with their own) [41]. Some participants suggested including aspects of social media as a part of the intervention experience; however, this idea was met with mixed opinions and some skepticism.

One increasingly viable intervention option that may serve to enhance relatedness in cancer survivors in mHealth interventions to some degree is the use of more sophisticated conversational technology, such as automated conversational agents, known as chatbots. Chatbots are increasingly being used as health intervention components $[48,49]$ and this emerging technology could help increase participant engagement and/or facilitate feelings of relatedness for some individuals while preserving the scalability of the intervention. Relatedness is theorized to influence health-related outcomes both directly and by impacting autonomous regulation [13]. Accordingly, targeting relatedness should be a priority for interventionists but the degree to which this psychological need can be met via electronic means is unclear. More research is needed to determine how mHealth interventions can meaningfully impact this construct in cancer survivors.

Research indicates that mHealth programs generally have high rates of participant discontinuation [50] and that participant engagement plays an important role in influencing the decision to continue an intervention $[41,42]$. In this study, Fitbit device wear was relatively high, and participants tended to rate the intervention favorably. However, the messages that requested a response were not well received. Individual interviews revealed that one potential barrier to this aspect of participant engagement was that the messages requesting a response sometimes required participants to engage in deeper reflection. This was generally perceived as inappropriate for the context in which participants tended to receive the messages (ie, when they were more active). Thus, one lesson learned from this study is to carefully consider the context in which intervention messages are to be received. We found that participants were not very likely to review past text messages, and this sentiment was echoed by participants' admission that they seldom accessed previously sent links to resources for healthy living. Future mHealth physical activity interventions could potentially increase engagement by configuring messages to be sent during lulls in physical activity that follow bouts of exercise (eg, at the conclusion of bouts of physical activity as registered by meeting a threshold level of Fitbit Active Minutes over a predetermined time period). This may be more conducive to participant engagement and serve as a useful opportunity to provide positive reinforcement and/or self-reflective, just-in-time support [51].

Our operationalization of participant response rate in this study was a summative measure of frequency. Future research should investigate what constitutes effective engagement or a broader conceptualization of engagement that relates more directly to desired intervention outcomes $[41,42]$. In this study, although the participant engagement feasibility criterion corresponding to the text message response rate was not met, participants in the experimental group tended to increase their physical activity levels more than their counterparts in the comparison group. A successful aspect of this study that helped facilitate participant engagement and high device wear was our inclusion of automated messages that were automatically sent if participants did not synchronize their Fitbit device for a prescribed period of time. The timestamp of users' last synchronization is available through the Fitbit application programming interface. In this study, we were able to use these data to help increase participants' engagement and data collection in a manner that minimized the use of study resources.

Although the experimental group reported increases in physical activity, the study results were mixed regarding whether participants felt that the Steps 2 Health messages motivated them to increase their physical activity levels. Interestingly, Zuckerman and Gal-Oz [52] noted a similar phenomenon regarding a discrepancy between the perceived and empirical effects of a gamified physical activity intervention. Participants may not necessarily attribute lifestyle changes to apparently effective gamification elements. Furthermore, we found no evidence that group assignment was associated with an increase in autonomous regulation. A review conducted by Johnson [53] 
revealed that the effects of gamification-centered wellness interventions are strongest for physical activity-related behavioral outcomes but weaker for motivation-related cognitions. Nonetheless, both the experimental and comparison groups exhibited a small, statistically significant increase in autonomous regulation. The provision of a wearable device alone could impact autonomous regulation in this population; however, this notion should be met with caution. The provision of consumer wearable technologies alone may undermine physical activity-related motivations in some populations [54] by emphasizing less autonomous forms of motivation, inducing anxiety and stigma, or by imposing unattainable or inappropriate norms [55].

Our findings indicated that the Steps2Health intervention was associated with an increase in self-reported exercise and device-measured step count during the intervention. Survey analyses provided evidence for a medium effect size from baseline to follow-up that is consistent with other mHealth-based behavioral interventions for promoting cancer survivors' physical activity [56,57]. This finding was supplemented by an analysis of device-measured step counts over the intervention period. The comparison group participants' step count was initially high but trended steadily downward. This is concordant with a waning novelty effect associated with physical activity device technologies [12]. The gamification aspects of the Steps 2 Health intervention may have influenced participants to gradually increase their step count. Future studies should further investigate these dynamics, as long-term physical activity maintenance is needed to best realize the diverse health benefits of physical activity. In some cases, it may be prudent to delay game design intervention components to capitalize on their effects and the novelty effect associated with the provision of physical activity tracking technologies. In fact, the Maintain IT Model of health behavior change posits that interventions centered on self-regulation may be appropriate for health behavior initiation, whereas interventions centered on precipitating a more centered and empowered state, consistent with SDT, may be more effective for leading to long-term health behavior maintenance [58].

\section{Study Limitations}

The establishment of the acceptability and feasibility of digital behavior change interventions is critically important, given their high initial costs and high rate of discontinuation of use. Furthermore, the CONSORT (Consolidated Standards of Reporting Trials) 2010 Statement Extension to Randomized Pilot and Feasibility Trials outlines the need for prespecified assessments of pilot trial objectives [59]. Unfortunately, there is a lack of consensus on the established criteria to aid researchers in determining the feasibility and acceptability of digital behavior change interventions. In this study, we set an a priori criteria for assessing the feasibility of Steps 2 Health based on the intervention's unique components (eg, text messaging contingent on physical activity tracker device-derived data), data observed in comparable studies (eg, for physical activity tracker wear), and the theoretical orientation of our intervention (ie, the emphasis on intrinsic motivation in SDT). However, we acknowledge that these criteria, and the thresholds we set for them, may not be applicable to other studies (or necessarily the ideal benchmarks for evaluating the feasibility of Steps 2 Health). Establishing universal quantitative criteria and corresponding thresholds may be a challenge, given the heterogeneous and rapidly evolving nature of digital behavior change interventions, but establishing basic metrics for commonly occurring physical activity intervention components may facilitate the conduct of rigorous research. Future research on this topic could make a meaningful contribution to the literature.

This study was limited by its small sample size and the use of convenience sampling recruitment methods. Participants may have been particularly motivated to change their physical activity levels from the outset, which may have interacted with the intervention components. The generalizability of the study's findings is limited by the fact that the study sample was relatively well educated and mostly female. Another limitation of this study is that we did not audio record the in-depth interviews and used field notes instead. Loss of details from field notes may have increased the risk of bias in the qualitative analysis. Furthermore, although every effort was made to capture insightful quotations accurately, some errors may have been introduced in this process. Nevertheless, associated threats to validity were reduced by our relatively straightforward applied research questions, short interviews, study staff members exclusively dedicated to taking field notes, and a research protocol specifying that the interviewer separately provided field notes immediately after all interviews. The measurement of physical activity via self-report has known limitations, and this is also true for consumer-grade wearable devices. Fitbit devices tend to overestimate step counts in free-living conditions, particularly for individuals with chronic disease and/or mobility limitations [38]. However, this study's limitations are offset by its notable strengths, including a randomized controlled design, a novel intervention approach, minimal loss to follow-up, the use of both quantitative and qualitative methods, and intervention qualities that lend themselves readily to widespread dissemination.

\section{Conclusions}

The findings of this study support the feasibility and acceptability of using the gamification of real-time step counts to increase cancer survivors' physical activity. Both the experimental and comparison groups increased their autonomous regulation for physical activity, and assignment to the experimental group was associated with increased physical activity. Coupling game design elements with wearable technologies is technically feasible and acceptable to cancer survivors and is potentially effective. More research is needed to develop these approaches as they have the potential to have a meaningful impact on public health. 


\section{Acknowledgments}

This research was made possible by the Center for Energy Balance in Cancer Prevention and Survivorship and by the Duncan Family Institute for Cancer Prevention and Risk Assessment, both at the University of Texas MD Anderson Cancer Center. MR was supported by the National Cancer Institute of the National Institutes of Health (F31 CA236433). This study used the assessment, intervention, and measurement (AIM) core by MD Anderson, a shared resource supported by the National Institutes of Health through MD Anderson's Cancer Center Support Grant (P30 CA016672). This study was supported by the Center for Energy Balance in Cancer Prevention and Survivorship, the Duncan Family Institute for Cancer Prevention and Risk Assessment, and a donation from Jason's Deli. The content of this paper is solely the responsibility of the authors and does not necessarily represent the official views of the National Institutes of Health. EL was supported by a Mentored Research Scholar Grant in Applied and Clinical Research from the American Cancer Society (MRSG-14-165-01-CPPB). YL was supported by a faculty fellowship from the Duncan Family Institute for Cancer Prevention and Risk Assessment.

\section{Authors' Contributions}

MR contributed to the conception of the study design, data collection, quantitative and qualitative data analysis, and drafting of the paper and provided approval of the version to be published. EL contributed to the conception of the study design, provided critical revision of the paper, and provided approval of the version to be published. YL contributed to quantitative data analysis, provided critical revision of the paper, and provided approval of the version to be published. MB contributed to the conception of the study design, data collection, and qualitative data analysis and provided approval of the version to be published. KBE contributed to the conception of the study design, data collection, quantitative and qualitative data analysis; provided critical revision of the paper; and provided approval of the version to be published.

\section{Conflicts of Interest}

None declared.

\section{Editorial Notice}

This randomized study was not registered. The authors explained that their study was "not an applicable clinical trial and did not require registration in the Clinical Trials Registry." The editor granted an exception of ICMJE rules for prospective registration of randomized trials because the risk of bias appears low. However, readers are advised to carefully assess the validity of any potential explicit or implicit claims related to primary outcomes or effectiveness.

\section{Multimedia Appendix 1}

Steps2Health interview guide.

[DOCX File, 20 KB-Multimedia Appendix 1]

\section{Multimedia Appendix 2}

Conceptual model for Steps2Health intervention.

[PNG File, $40 \mathrm{~KB}-\underline{\text { Multimedia Appendix 2] }}$

\section{Multimedia Appendix 3}

Mean Godin Leisure-Time Physical Activity Questionnaire scores by group at baseline and follow-up. Error bars indicate 95\% CIs.

[PNG File, 23 KB-Multimedia Appendix 3]

\section{Multimedia Appendix 4}

Spaghetti plots of mean (thick) and subject-specific (thin) step count trajectories for the comparison and experimental groups during the intervention period.

[PNG File, 39 KB-Multimedia Appendix 4]

\section{Multimedia Appendix 5}

Raw and fitted step count trajectories for individual participants in the experimental group.

[PNG File, 84 KB-Multimedia Appendix 5]

\section{Multimedia Appendix 6}

Raw and fitted step count trajectories for individual participants in the comparison group. 


\section{References}

1. Ballard-Barbash R, Friedenreich CM, Courneya KS, Siddiqi SM, McTiernan A, Alfano CM. Physical activity, biomarkers, and disease outcomes in cancer survivors: a systematic review. J Natl Cancer Inst 2012 Jun 6;104(11):815-840 [FREE Full text] [doi: 10.1093/jnci/djs207] [Medline: 22570317]

2. Mishra SI, Scherer RW, Geigle PM, Berlanstein DR, Topaloglu O, Gotay CC, et al. Exercise interventions on health-related quality of life for cancer survivors. Cochrane Database Syst Rev 2012 Aug 15(8):CD007566 [FREE Full text] [doi: 10.1002/14651858.CD007566.pub2] [Medline: 22895961]

3. Piercy KL, Troiano RP, Ballard RM, Carlson SA, Fulton JE, Galuska DA, et al. The physical activity guidelines for Americans. J Am Med Assoc 2018 Nov 20;320(19):2020-2028. [doi: 10.1001/jama.2018.14854] [Medline: 30418471]

4. Tarasenko Y, Chen C, Schoenberg N. Self-reported physical activity levels of older cancer survivors: results from the 2014 national health interview survey. J Am Geriatr Soc 2017 Feb;65(2):e39-e44. [doi: 10.1111/jgs.14589] [Medline: 27943255]

5. Loprinzi PD, Lee H, Cardinal BJ. Objectively measured physical activity among US cancer survivors: considerations by weight status. J Cancer Surviv 2013 Sep;7(3):493-499. [doi: 10.1007/s11764-013-0293-7] [Medline: 23686709]

6. Thraen-Borowski KM, Gennuso KP, Cadmus-Bertram L. Accelerometer-derived physical activity and sedentary time by cancer type in the United States. PLoS One 2017;12(8):e0182554 [FREE Full text] [doi: 10.1371/journal.pone.0182554] [Medline: 28806753]

7. Milne HM, Guilfoyle A, Gordon S, Wallman KE, Courneya KS. Personal accounts of exercise and quality of life from the perspective of breast cancer survivors. Qual Life Res 2007 Nov;16(9):1473-1481. [doi: 10.1007/s11136-007-9251-z] [Medline: $\underline{17717726]}$

8. Smith L, Croker H, Fisher A, Williams K, Wardle J, Beeken RJ. Cancer survivors' attitudes towards and knowledge of physical activity, sources of information, and barriers and facilitators of engagement: A qualitative study. Eur J Cancer Care (Engl) 2017 Jul;26(4):-. [doi: 10.1111/ecc.12641] [Medline: 28135016]

9. Haberlin C, O'Dwyer T, Mockler D, Moran J, O'Donnell DM, Broderick J. The use of eHealth to promote physical activity in cancer survivors: a systematic review. Support Care Cancer 2018 Oct;26(10):3323-3336. [doi: 10.1007/s00520-018-4305-z] [Medline: 29909476]

10. Schaffer K, Panneerselvam N, Loh KP, Herrmann R, Kleckner IR, Dunne RF, et al. Systematic review of randomized controlled trials of exercise interventions using digital activity trackers in patients with cancer. J Natl Compr Canc Netw 2019 Jan;17(1):57-63 [FREE Full text] [doi: 10.6004/jnccn.2018.7082] [Medline: 30659130]

11. Thomas R. 25\% of Users Abandon Apps After One Use. Localytics. 2019. URL: https://tinyurl.com/y6qbn981 [accessed 2020-10-16]

12. Shin G, Feng Y, Jarrahi M, Gafinowitz N. Beyond novelty effect: a mixed-methods exploration into the motivation for long-term activity tracker use. JAMIA Open 2019 Apr;2(1):62-72 [FREE Full text] [doi: 10.1093/jamiaopen/ooy048] [Medline: $\underline{31984346}$ ]

13. Ryan RM, Deci EL. Self-determination theory and the facilitation of intrinsic motivation, social development, and well-being. Am Psychol 2000 Jan;55(1):68-78. [doi: 10.1037//0003-066x.55.1.68] [Medline: 11392867]

14. Teixeira PJ, Carraça EV, Markland D, Silva MN, Ryan RM. Exercise, physical activity, and self-determination theory: a systematic review. Int J Behav Nutr Phys Act 2012 Jun 22;9:78 [FREE Full text] [doi: 10.1186/1479-5868-9-78] [Medline: 22726453]

15. Milne HM, Wallman KE, Guilfoyle A, Gordon S, Corneya KS. Self-determination theory and physical activity among breast cancer survivors. J Sport Exerc Psychol 2008 Feb;30(1):23-38. [doi: 10.1123/jsep.30.1.23] [Medline: 18369241]

16. Mayer DK, Landucci G, Awoyinka L, Atwood AK, Carmack CL, Demark-Wahnefried W, et al. SurvivorCHESS to increase physical activity in colon cancer survivors: can we get them moving? J Cancer Surviv 2018 Feb;12(1):82-94 [REEE Full text] [doi: 10.1007/s11764-017-0647-7] [Medline: 28994035]

17. Mendoza JA, Baker KS, Moreno MA, Whitlock K, Abbey-Lambertz M, Waite A, et al. A Fitbit and Facebook mHealth intervention for promoting physical activity among adolescent and young adult childhood cancer survivors: A pilot study. Pediatr Blood Cancer 2017 Dec;64(12):-. [doi: 10.1002/pbc.26660] [Medline: 28618158]

18. Przybylski A, Rigby C, Ryan R. A motivational model of video game engagement. Rev General Psychol 2010 Jun;14(2):154-166. [doi: 10.1037/a0019440]

19. Lyons EJ, Tate DF, Ward DS, Ribisl KM, Bowling JM, Kalyanaraman S. Engagement, enjoyment, and energy expenditure during active video game play. Health Psychol 2014 Feb;33(2):174-181 [FREE Full text] [doi: 10.1037/a0031947] [Medline: 23527520]

20. Sailer M, Hense J, Mayr S, Mandl H. How gamification motivates: an experimental study of the effects of specific game design elements on psychological need satisfaction. Comput Hum Behav 2017 Apr;69:371-380. [doi:

10.1016/j.chb.2016.12.033]

21. Deterding S. The lens of intrinsic skill atoms: a method for gameful design. Hum-Comput Interac 2015 May 15;30(3-4):294-335. [doi: 10.1080/07370024.2014.993471] 
22. Michie S, van Stralen MM, West R. The behaviour change wheel: a new method for characterising and designing behaviour change interventions. Implement Sci 2011 Apr 23;6:42 [FREE Full text] [doi: 10.1186/1748-5908-6-42] [Medline: 21513547]

23. Lucero A, Holopainen J, Ollila E, Suomela R, Karapanos E. The playful experiences (PLEX) framework as a guide for expert evaluation. In: The 6th International Conference on Designing Pleasurable Products and Interfaces. 2013 Presented at: PLEX'13; September, 2013; Newcastle upon Tyne. [doi: 10.1145/2513506.2513530]

24. Baranowski T, Lyons EJ, Thompson D. Experimental design to systematically develop a knowledge base for effective games for health. Games Health J 2019 Oct;8(5):307-312. [doi: 10.1089/g4h.2019.0057] [Medline: 31157990]

25. Hayes SC. Acceptance and commitment therapy, relational frame theory, and the third wave of behavioral and cognitive therapies - republished article. Behav Ther 2016 Nov;47(6):869-885. [doi: 10.1016/j.beth.2016.11.006] [Medline: 27993338]

26. Miller W, Rollnick S. Motivational interviewing Helping People Change. New York, USA: The Guilford Press; 2013.

27. Schmitz KH, Courneya KS, Matthews C, Demark-Wahnefried W, Galvão DA, Pinto BM, American College of Sports Medicine. American College of Sports Medicine roundtable on exercise guidelines for cancer survivors. Med Sci Sports Exerc 2010 Jul;42(7):1409-1426. [doi: 10.1249/MSS.0b013e3181e0c112] [Medline: 20559064]

28. Shephard R. Godin Leisure-Time Exercise Questionnaire. Medicine\&amp Science in Sports \&amp Exercise 1997 Jun;29(Supplement):36-38 [FREE Full text] [doi: 10.1097/00005768-199706001-00009]

29. Robertson MC, Tsai E, Lyons EJ, Srinivasan S, Swartz MC, Baum ML, et al. Mobile health physical activity intervention preferences in cancer survivors: a qualitative study. JMIR Mhealth Uhealth 2017 Jan 24;5(1):e3 [FREE Full text] [doi: 10.2196/mhealth.6970] [Medline: 28119278]

30. Brickwood K, Watson G, O'Brien J, Williams AD. Consumer-based wearable activity trackers increase physical activity participation: systematic review and meta-analysis. JMIR Mhealth Uhealth 2019 Apr 12;7(4):e11819 [FREE Full text] [doi: 10.2196/11819] [Medline: 30977740]

31. Peddle CJ, Plotnikoff RC, Wild TC, Au H, Courneya KS. Medical, demographic, and psychosocial correlates of exercise in colorectal cancer survivors: an application of self-determination theory. Support Care Cancer 2008 Jan;16(1):9-17. [doi: 10.1007/s00520-007-0272-5] [Medline: 17569994]

32. Schmitz KH, Campbell AM, Stuiver MM, Pinto BM, Schwartz AL, Morris GS, et al. Exercise is medicine in oncology: engaging clinicians to help patients move through cancer. CA Cancer J Clin 2019 Nov;69(6):468-484 [FREE Full text] [doi: 10.3322/caac.21579] [Medline: 31617590]

33. Liao Y, Robertson MC, Winne A, Wu IH, Le TA, Balachandran DD, et al. Investigating the within-person relationships between activity levels and sleep duration using Fitbit data. Transl Behav Med 2020 Jul 15 epub ahead of print. [doi: 10.1093/tbm/ibaa071] [Medline: $\underline{32667039}$ ]

34. Chu AH, Ng SH, Paknezhad M, Gauterin A, Koh D, Brown MS, et al. Comparison of wrist-worn Fitbit Flex and waist-worn ActiGraph for measuring steps in free-living adults. PLoS One 2017;12(2):e0172535 [FREE Full text] [doi: 10.1371/journal.pone.0172535] [Medline: 28234953]

35. Tudor-Locke C, Barreira TV, Schuna JM. Comparison of step outputs for waist and wrist accelerometer attachment sites. Med Sci Sports Exerc 2015 Apr;47(4):839-842. [doi: 10.1249/MSS.0000000000000476] [Medline: 25121517]

36. Choi L, Liu Z, Matthews CE, Buchowski MS. Validation of accelerometer wear and nonwear time classification algorithm. Med Sci Sports Exerc 2011 Feb;43(2):357-364 [FREE Full text] [doi: 10.1249/MSS.0b013e3181ed61a3] [Medline: 20581716]

37. Collins JE, Yang HY, Trentadue TP, Gong Y, Losina E. Validation of the Fitbit Charge 2 compared to the ActiGraph GT3X+ in older adults with knee osteoarthritis in free-living conditions. PLoS One 2019;14(1):e0211231 [FREE Full text] [doi: 10.1371/journal.pone.0211231] [Medline: 30699159]

38. Hsieh H, Shannon SE. Three approaches to qualitative content analysis. Qual Health Res 2005 Nov;15(9):1277-1288. [doi: 10.1177/1049732305276687] [Medline: 16204405]

39. Silva SS, Jayawardana MW, Meyer D. Statistical methods to model and evaluate physical activity programs, using step counts: a systematic review. PLoS One 2018;13(11):e0206763 [FREE Full text] [doi: 10.1371/journal.pone.0206763] [Medline: 30388164]

40. Bolger N, Laurenceau J. In: Kenny D, Little T, editors. Intensive Longitudinal Methods: an Introduction to Diary and Experience Sampling Research. New York, USA: Guilford Press; 2013.

41. Yardley L, Spring BJ, Riper H, Morrison LG, Crane DH, Curtis K, et al. Understanding and promoting effective engagement with digital behavior change interventions. Am J Prev Med 2016 Nov;51(5):833-842. [doi: 10.1016/j.amepre.2016.06.015] [Medline: 27745683]

42. Michie S, Yardley L, West R, Patrick K, Greaves F. Developing and evaluating digital interventions to promote behavior change in health and health care: recommendations resulting from an international workshop. J Med Internet Res 2017 Jun 29;19(6):e232 [FREE Full text] [doi: 10.2196/jmir.7126] [Medline: 28663162]

43. Hartman SJ, Marinac CR, Bellettiere J, Godbole S, Natarajan L, Patterson RE, et al. Objectively measured sedentary behavior and quality of life among survivors of early stage breast cancer. Support Care Cancer 2017 Aug;25(8):2495-2503 [FREE Full text] [doi: 10.1007/s00520-017-3657-0] [Medline: 28326507] 
44. Maxwell-Smith C, Hince D, Cohen PA, Bulsara MK, Boyle T, Platell C, et al. A randomized controlled trial of WATAAP to promote physical activity in colorectal and endometrial cancer survivors. Psychooncology 2019 Jul;28(7):1420-1429. [doi: 10.1002/pon.5090] [Medline: $\underline{\text { 30980691] }}$

45. Nicholoson S. A RECIPE for Meaningful Gamification. In: Reiners T, Wood LC, editors. Gamification in Education and Business. Cham: Springer; 2015:1-20.

46. Tsai E, Robertson MC, Lyons EJ, Swartz MC, Basen-Engquist K. Physical activity and exercise self-regulation in cancer survivors: a qualitative study. Psychooncology 2018 Feb;27(2):563-568 [FREE Full text] [doi: 10.1002/pon.4519] [Medline: 28763133]

47. Zhang J, Brackbill D, Yang S, Becker J, Herbert N, Centola D. Support or competition? How online social networks increase physical activity: a randomized controlled trial. Prev Med Rep 2016 Dec;4:453-458 [FREE Full text] [doi: 10.1016/j.pmedr.2016.08.008] [Medline: 27617191]

48. Pereira J, Díaz O. Using health chatbots for behavior change: a mapping study. J Med Syst 2019 Apr 4;43(5):135. [doi: 10.1007/s10916-019-1237-1] [Medline: 30949846]

49. Kowatsch T, Nißen M, Rüegger D, Stieger M, Flückiger C, Allemand M, et al. The Impact of Interpersonal Closeness Cues in Text-based Healthcare Chatbots on Attachment Bond and the Desire to Continue Interacting: an Experimental Design. In: 26th European Conference on Information Systems. 2018 May Presented at: CIS'18; June 23, 2018; Portsmouth, UK URL: https://www.alexandria.unisg.ch/publications/254284

50. Eysenbach G. The law of attrition. J Med Internet Res 2005 Mar 31;7(1):e11 [FREE Full text] [doi: 10.2196/jmir.7.1.e11] [Medline: 15829473 ]

51. Nahum-Shani I, Smith S, Spring B, Collins LM, Witkiewitz K, Tewari A, et al. Just-in-time adaptive interventions (JITAIs) in mobile health: key components and design principles for ongoing health behavior support. Ann Behav Med 2018 May 18;52(6):446-462. [doi: 10.1007/s12160-016-9830-8] [Medline: 27663578]

52. Zuckerman $\mathrm{O}, \mathrm{Gal}-\mathrm{Oz} \mathrm{A}$. Deconstructing gamification: evaluating the effectiveness of continuous measurement, virtual rewards, and social comparison for promoting physical activity. Pers Ubiquit Comput 2014 Jul 5;18(7):1705-1719 [FREE Full text] [doi: 10.1007/s00779-014-0783-2]

53. Johnson D, Deterding S, Kuhn K, Staneva A, Stoyanov S, Hides L. Gamification for health and wellbeing: a systematic review of the literature. Internet Interv 2016 Nov;6:89-106 [FREE Full text] [doi: 10.1016/j.invent.2016.10.002] [Medline: $\underline{30135818]}$

54. Kerner C, Goodyear V. The motivational impact of wearable healthy lifestyle technologies: a self-determination perspective on fitbits with adolescents. Am J Health Educ 2017 Jul 28;48(5):287-297 [FREE Full text] [doi: 10.1080/19325037.2017.1343161]

55. Owens J, Cribb A. 'My fitbit thinks I can do better!' do health promoting wearable technologies support personal autonomy? PhilosTechnol 2017 Jun 6;32(1):23-38 [FREE Full text] [doi: 10.1007/s13347-017-0266-2]

56. Kiss N, Baguley BJ, Ball K, Daly RM, Fraser SF, Granger CL, et al. Technology-supported self-guided nutrition and physical activity interventions for adults with cancer: systematic review. JMIR Mhealth Uhealth 2019 Feb 12;7(2):e12281 [FREE Full text] [doi: 10.2196/12281] [Medline: $\underline{\text { 30747720] }}$

57. Roberts AL, Fisher A, Smith L, Heinrich M, Potts HW. Digital health behaviour change interventions targeting physical activity and diet in cancer survivors: a systematic review and meta-analysis. J Cancer Surviv 2017 Dec;11(6):704-719 [FREE Full text] [doi: $10.1007 / \mathrm{s} 11764-017-0632-1]$ [Medline: 28779220]

58. Caldwell AE, Masters KS, Peters JC, Bryan AD, Grigsby J, Hooker SA, et al. Harnessing centred identity transformation to reduce executive function burden for maintenance of health behaviour change: the Maintain IT model. Health Psychol Rev 2018 Sep;12(3):231-253 [FREE Full text] [doi: 10.1080/17437199.2018.1437551] [Medline: 29402182]

59. Eldridge SM, Chan CL, Campbell MJ, Bond CM, Hopewell S, Thabane L, PAFS consensus group. CONSORT 2010 statement: extension to randomised pilot and feasibility trials. Br Med J 2016 Oct 24;355:i5239. [doi: 10.1136/bmj.i5239] [Medline: 27777223]

\footnotetext{
Abbreviations

BREQ-3: Behavioral Regulation for Exercise Questionnaire-3

mHealth: mobile health

MMS: multimedia messaging service

SDT: Self-Determination Theory
} 
Edited by G Eysenbach; submitted 21.02.20; peer-reviewed by N Ridgers, $R$ Rahman, C Romanzini, L Grepo, AS Lu; comments to author 29.06.20; revised version received 24.08.20; accepted 15.09.20; published 24.11.20

Please cite as:

Robertson MC, Lyons EJ, Liao Y, Baum ML, Basen-Engquist KM

Gamified Text Messaging Contingent on Device-Measured Steps: Randomized Feasibility Study of a Physical Activity Intervention for Cancer Survivors

JMIR Mhealth Uhealth 2020;8(11):e18364

URL: https://mhealth.jmir.org/2020/11/e18364

doi: $\underline{10.2196 / 18364}$

PMID: 33231551

(CMichael C Robertson, Elizabeth J Lyons, Yue Liao, Miranda L Baum, Karen M Basen-Engquist. Originally published in JMIR mHealth and uHealth (http://mhealth.jmir.org), 24.11.2020. This is an open-access article distributed under the terms of the Creative Commons Attribution License (https://creativecommons.org/licenses/by/4.0/), which permits unrestricted use, distribution, and reproduction in any medium, provided the original work, first published in JMIR mHealth and uHealth, is properly cited. The complete bibliographic information, a link to the original publication on http://mhealth.jmir.org/, as well as this copyright and license information must be included. 